\title{
EVALUATION OF MOISTURE MANAGEMENT PROPERTIES OF KNITTED FABRICS DYED WITH CANNON BALL FRUIT EXTRACT
}

\author{
SHASHIKALA. H $^{1,2} \&$ S. KAUVERY BAI ${ }^{3}$ \\ ${ }^{l}$ HOD-UG/PG, Army Institute of Fashion \& Design, Bengaluru, Karnataka, India \\ ${ }^{2}$ Research Scholar, Smt. VHD Central Institute of Home Science, Bangalore, Karnataka, India
}

${ }^{3}$ Head, Department of Textiles and Clothing, Smt. VHD Central Institute of Home Science, Bangalore, Karnataka, India

Moisture Management Property of fabrics is the ability to transport the liquid moisture from skin to the outer surface of the garment. Moisture management is of prime importance in present-day context as today's consumers not only look for aesthetics but also comfort in clothing.

The present paper discusses on overall moisture management properties of selected knitted fabrics (Cotton, Modal, Bamboo and Silk) dyed with cannonball fruit extract using alum and pomegranate rind as mordants. Moisture management properties, such as wetting time of top and bottom fabric surfaces, maximum moisture absorption rates of top and bottom surfaces, maximum wetted radii of top and bottom surfaces, spreading speeds of top and bottom surfaces, and cumulative one-way transport capacity and overall moisture management capacity have been considered and correlated to the dyedcotton, silk, modal and bamboo single jersey knitted fabrics. Cotton and Silk show almost similar performance in absorption rate and AOTI is well related to OMMC. Silk shows the higher value ofAOTI and its performance is found to be very good. However the performance ofall dyed fabrics is rated as very good.

KEYWORDS: Cannon Ball Fruit, Knitted Fabrics, Accumulative One Way Transport Index (Aoti) \& Overall Moisture Management Properties(Omcc)
\end{abstract}

Received: Dec 06, 2018; Accepted: Dec 26, 2018; Published: Jan 18, 2019; Paper Id.: IJTFTAPR20191

\section{INTRODUCTION}

Moisture management properties of any textiles are very crucial as they control the transport of moisture which directly influences the wearer's comfort. The Overall Moisture Management Capacity(OMMC) can be determined by combining five parameters such as Wetting time of top and bottom fabric surfaces, Absorption rates of top and bottom surfaces, Maximum wetted radii of top and bottom surfaces, Spreading speeds of top and bottom surfaces, and Accumulative one-way transport index.

Knitting is the method of making fabric by formation of loops. The knitted fabric structure depends upon the yarns that run horizontally (courses) and vertically (wales) respectively. Knitted fabrics are preferred for making sportswear, intimate wear etc as they have more freedom of movement, better stretch ability, permeability and moisture absorbency and hence possess good comfort properties.

It is indeed remarkable that there are many papers on OMMC of knitted fabrics produced with blends, plated fabrics and bilayer fabrics. A recent paper by Jhanji et.al(2015) ${ }^{2}$ is concerned with the moisture management properties of plated fabrics. 
Although a considerable work has been done on overall moisture management capacity of fabrics regarding the overall moisture management capacity of natural dyed selected knitted fabrics is scanty. Hence the present paper discusses on the overall moisture management properties of cotton, modal, bamboo and silk knitted fabrics with addition of lycra and dyed with natural dye(cannonball fruit extract) and constructed for Active wear to find out their suitability for sportswear.

\section{MATERIALS AND METHODS}

\section{Fabric Preparation}

Commercially available $100 \%$ cotton, $100 \%$ bamboo, $100 \%$ modal and $100 \%$ silk were sourced from Tirupur, India. It was ensured that all of the yarns purchased had the same mean linear density of 40 (Ne 14.68tex). The above yarns were used to produce single jersey fabrics on circular knitting machines of the following details: Single jersey machine, model MV4, gauge 32 GG, diameter 36", speed $25 \mathrm{rpm}$, feeders 74 and number of needles 2640; the ambient knitting-room atmosphere had a humidity of $65 \%$ and a temperature of $30 \pm 2^{\circ} \mathrm{C}$. Samples were produced with same loop-length value of $2.5 \mathrm{~mm}$ fabrics respectively. The knitting process was completed with constant machine settings and the samples were kept in standard atmosphere for 24 hours to allow for relaxation and conditioning. The samples were scoured at $40{ }^{\circ} \mathrm{C}$ for 30 minutes followed by rinsing for the same time period. After the scouring process was completed, the samples were dried.

\section{Dyeing}

Alum and pomegranate rind were used as mordants by simultaneous mordanting technique for better dye ability. Cannonball fruit extract was used and the dye was extracted in aqueous medium and dyeing was carried out using soft flow dyeing machine. The dyed fabrics were taken out after 30 minutes and were tested for overall moisture management properties.

\section{Testing}

For dimensional properties, the number of wales and courses per inch were measured. The number of wales and courses per inch were determined by taking 10 measurements from different areas of each fabric. Mean values were calculated. Fabric thickness was measured on SDL digital thickness gauge according to ISO 5084 standard. The basic geometric properties of the fabrics, such as thickness $(\mathrm{mm})$ and weight per unit area $\left(\mathrm{g} / \mathrm{m}^{2}\right)$ and fabric count are given in Table 1.

Table 1: Basic Geometric Properties of Selected Knitted Fabrics

\begin{tabular}{|c|c|c|c|c|c|c|c|c|c|c|c|c|}
\hline \multirow{3}{*}{ Fabrics } & \multirow{2}{*}{\multicolumn{3}{|c|}{ Fabric Thickness (mm) }} & \multirow{2}{*}{\multicolumn{3}{|c|}{ Fabric Weight $\left(\mathbf{m g} / \mathrm{cm}^{2}\right)$}} & \multicolumn{6}{|c|}{ Fabric Count } \\
\hline & & & & & & & \multicolumn{3}{|c|}{ Wales/cm } & \multicolumn{3}{|c|}{ Courses/cm } \\
\hline & $\mathbf{C}$ & $\mathbf{A M}$ & LPM & $\mathbf{C}$ & $\mathbf{A M}$ & LPM & $\mathbf{C}$ & AM & LPM & $\mathbf{C}$ & $\mathbf{A M}$ & LPM \\
\hline Modal & 0.422 & 0.466 & 0.464 & 11.42 & 13.92 & 13.92 & 14 & 16 & 17 & 23 & 26 & 25 \\
\hline Silk & 0.469 & 0.488 & 0.493 & 10.83 & 11.37 & 11.40 & 14 & 16 & 18 & 20 & 22 & 23 \\
\hline Cotton & 0.506 & 0.691 & 0.688 & 12.13 & 14.12 & 14.15 & 13 & 15 & 16 & 22 & 23 & 24 \\
\hline Bamboo & 0.438 & 0.478 & 0.474 & 12.75 & 13.54 & 13.52 & 15 & 16 & 18 & 22 & 24 & 23 \\
\hline
\end{tabular}

Note: C - Controlled Fabric, AM -Alum Mordanted, LPM -Lycra Pomegranate Mordanted

It can be inferred from the above table that dyed fabrics show a slight increase in thickness and weight when compared to the controlled fabrics this may be due to fabric set. 


\section{Overall Moisture Management Capacity}

The fabrics were tested using overall moisture management tester (MMT) developed by Hu et.al (2005). This has been accepted by American Association of Textile Chemists and Colourists (AATCC) as a test method. This test is designated as TM 195 is used for measuring the moisture handling properties of fabrics for active wear and other apparels.

The MMT tester provides 5 major indices to characterize moisture management properties of fabrics.

- Wetting Time Top $\left(\mathrm{WT}_{\mathrm{t}}\right)$ and bottom $\left(\mathrm{WT}_{\mathrm{b}}\right)$ surface is the time periods in which the top and bottom surfaces of the fabric just start to get wetted respectively after the test commences which are defined as the time in seconds (sec). When the slope of total water contents at the top and bottom surfaces (i.e. $U_{\text {top }}$ and $U_{\text {bottom }}$ ) become greater than Tan $\left(15^{0}\right)$ respectively. Wetting time can be compared with the absorbency drop test specified in AATCC 79.

- Absorption Rate Top $\left(\mathrm{AR}_{\mathrm{t}}\right)$ and bottom $\left(\mathrm{AR}_{\mathrm{b}}\right)$ are the average moisture absorption (\% sec) ability of the fabric top and bottom surfaces within in the pumping time respectively.

- Maximum Wetted Radius $\left(\mathrm{MWR}_{\mathrm{t}}\right.$ and $\mathrm{MWR}_{\mathrm{b}}$ ) are the indices defined as maximum wetted ring radius at the top and bottom surfaces respectively, where the slopes of the total water content $\left(\mathrm{U}_{\text {top }}\right.$ or $\left.\mathrm{U}_{\text {bottom }}\right)$ become greater than the $\operatorname{Tan}\left(15^{\circ}\right)$ for the top and bottom surfaces respectively. Maximum wetting radius of fabrics is measured in 'mm'.

- Spreading Speed $\left(\mathrm{SS}_{\mathrm{t}}\right.$ and $\mathrm{SS}_{\mathrm{b}}$ ) measured in $\mathrm{mm} / \mathrm{second}$ is defined as the accumulative spreading speed from the center to the maximum wetted radius.

- Accumulative one-way transport index ( $\mathrm{R}$ ) is the difference in the accumulative moisture content between the two surfaces of the fabric. AOTI is a very important parameter which affects OMMC.

$$
\mathrm{R}=\frac{\left\{\operatorname{Area}\left(\mathrm{U}_{\mathrm{b}}\right)-\operatorname{Area}\left(\mathrm{U}_{\mathrm{t}}\right)\right\}}{\text { Total testing time }}
$$

By combining the above parameters, an index called Overall Moisture Management Capacity (OMMC) can be derived. OMMC is an index which indicates the overall capability of the fabric to manage the transport of liquid moisture. The larger the OMMC, the higher the overall moisture management ability of the fabrics.

Table 2: Moisture Management Properties of Selected Knitted Fabrics

\begin{tabular}{|c|c|c|c|c|c|c|c|c|c|c|c|c|}
\hline $\begin{array}{c}\text { Fabrics/ } \\
\text { Parameters }\end{array}$ & M & MA & MLP & C & CA & CLP & S & SA & SLP & B & BA & BLP \\
\hline $\mathrm{WT}_{\text {top }}(\mathrm{sec})$ & 2.78 & 4.36 & 8.91 & 5.91 & 7.56 & 13.38 & 4.58 & 6.05 & 8.01 & 3.38 & 7.89 & 8.82 \\
\hline $\mathrm{WT}_{\text {bottom }}(\mathrm{sec})$ & 2.82 & 4.51 & 9.17 & 6.38 & 8.44 & 15.31 & 5.14 & 7.56 & 9.15 & 4.75 & 8.42 & 9.56 \\
\hline $\mathrm{AR}_{\text {top }}(\% / \mathrm{sec})$ & 53.14 & 48.79 & 31.33 & 42.03 & 49.56 & 55.16 & 40.28 & 47.83 & 9.88 & 42.29 & 49.70 & 52.72 \\
\hline $\mathrm{AR}_{\text {bottom }}(\% / \mathrm{sec})$ & 53.81 & 68.93 & 45.98 & 46.38 & 56.29 & 66.65 & 45.62 & 49.41 & 51.55 & 55.91 & 64.45 & 69.92 \\
\hline $\mathrm{MWR}_{\text {top }}(\mathrm{mm})$ & 15.0 & 16.0 & 17.0 & 20 & 24.0 & 26.0 & 10.0 & 12.0 & 14.0 & 17.0 & 18.0 & 19.0 \\
\hline $\mathrm{MWR}_{\text {bottom }}(\mathrm{mm})$ & 16.0 & 15.0 & 18.0 & 22.0 & 26.0 & 28.0 & 11.0 & 13.0 & 15.0 & 18.0 & 19.0 & 20.0 \\
\hline $\mathrm{SS}_{\text {top }}(\mathrm{mm} / \mathrm{sec})$ & 2.77 & 2.98 & 3.27 & 4.56 & 4.76 & 4.99 & 1.23 & 1.68 & 2.33 & 3.03 & 3.21 & 3.47 \\
\hline $\mathrm{SS}_{\text {bottom }}(\mathrm{mm} / \mathrm{sec})$ & 2.49 & 2.76 & 2.98 & 4.23 & 4.52 & 4.02 & 0.96 & 1.52 & 2.23 & 2.89 & 3.11 & 3.22 \\
\hline $\mathrm{AOTI}(\%)$ & 90.06 & 166.3 & 194.85 & 549.26 & 563.68 & 746.37 & 684.7 & 758.65 & 853.6 & 144.2 & 214.09 & 303.51 \\
\hline $\mathrm{OMMC}$ & 0.51 & 0.49 & 0.40 & 0.60 & 0.52 & 0.51 & 0.60 & 0.60 & 0.58 & 0.59 & 0.48 & 0.46 \\
\hline
\end{tabular}

Note:

M- 100\% Modal, MA- Modal Alum mordanted, Modal Lycra Pomegranate mordanted 
S- $100 \%$ Silk, SA- Silk Alum mordanted, SLP - Silk Lycra Pomegranate mordanted

C- $100 \%$ Cotton, CA- Cotton Alum mordanted, Cotton Lycra Pomegranate mordanted

B- 100\% Bamboo, BA- Bamboo Alum mordanted, BLP-Bamboo Lycra Pomegranate mordanted.

\section{RESULTS AND DISCUSSIONS}

In this study the moisture management properties of cotton, modal, silk and bamboo knitted fabrics were studied before and after dyeing. Table 2 represents the moisture management properties of controlled fabrics (modal, cotton, silk and bamboo) which were compared with that of alum mordanted dyed (modal, cotton, silk and bamboo) and pomegranate mordanted dyed (modal, cotton, silk and bamboo) lycra fabrics . It was noticed that in the undyed state cotton, silk and bamboo were identical in moisture absorption while modal was found to have a lower value. It is also evident from Table 2 that AOTI is well related to OMMC. Silk showed the higher value of AOTI and its performance was found to be very good.

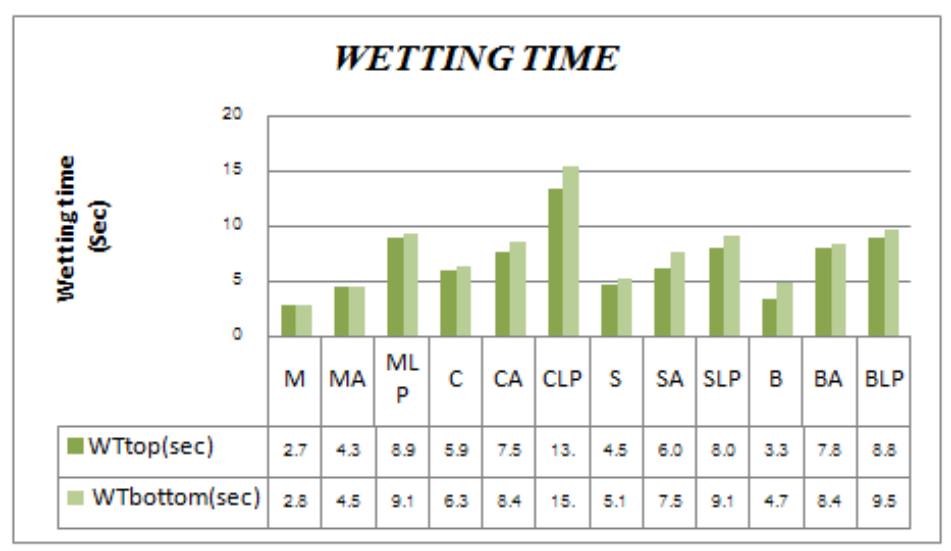

Figure 1

The wetting time values in seconds of the top and bottom surfaces of the fabrics are given in Figure 1. Wetting time top (WTt) and wetting time bottom (WTb) are the time periods in which the top and bottom surfaces of the fabric start on to wet after the initiation of the test. It can be seen that the wetting time for both top and bottom sides of the fabrics changes with dyeing. The results show that the wetting time of the bottom surface is in general higher than that the top surface for all the fabrics. It can be explained that the wetting time value is related with the water absorbency of fabrics. It was observed thatthe wetting time top and wetting time bottom of all the dyed fabrics exhibited higher wetting time than controlled fabrics. Also pomegranate mordanted dyed fabrics showed higher wetting time in all the four cases than alum mordanted dyed fabrics. Thus, the higher the thickness in fabrics the higher is the wetting time. Also, as bamboo and modal had lower thickness (Table 1) reveal lower wetting time compare to cotton and silk fabrics. Karthikeyan et al $(2016)^{3}$ avowed that thinner fabrics be evidence for faster wetting than thicker ones, when equal amounts of water are applied. Moreover, as the bamboo and modal yarns had lower bending rigidity, the knitted loops in the fabric can be compressed more easily and result in lower fabric thickness, a finding that also contributes to the lower wetting time of the bamboo and modal knitted fabrics (Prakash et al. 2013) ${ }^{4}$. Hence it can be concluded that the wetting time values for both top and bottom surfaces has increased after dyeing in all cases this may be due to fabric set. 


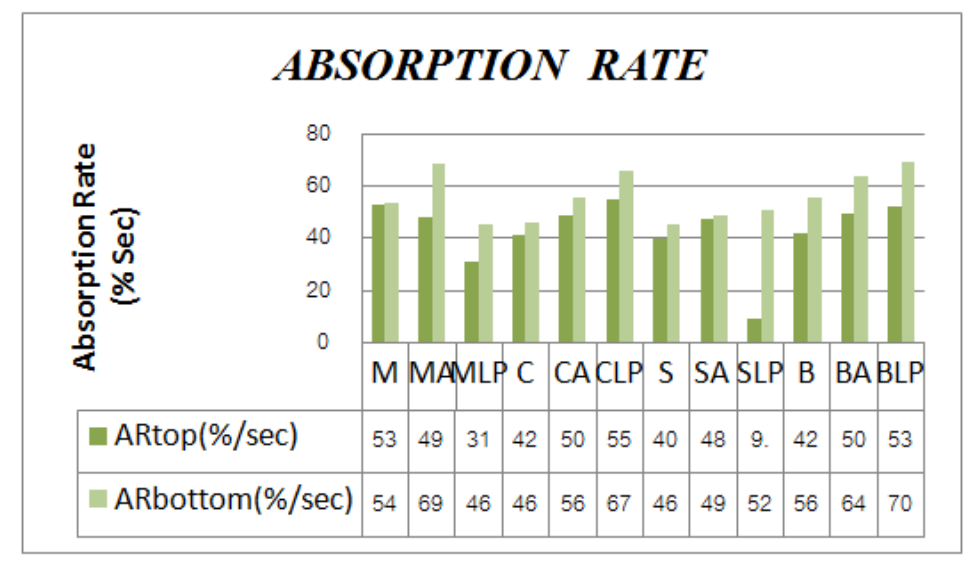

Figure 2

The absorption rates of the top and bottom surfaces of the fabrics are given in Figure 2. As noted earlier (Table 1), fabric thickness increases for the dyed fabrics. The thinner the fabric, the greater is the absorption rate. According to Figure 2, pomegranate mordanted dyed fabrics showed higher absorption rate in all the four cases than alum mordanted dyed fabrics. It is also observed that the absorption rates of the bottom surfaces of the fabrics are generally higher than those of the top surfaces. This indicates that most of the liquid moisture gets distributed on the bottom surface of the fabrics.

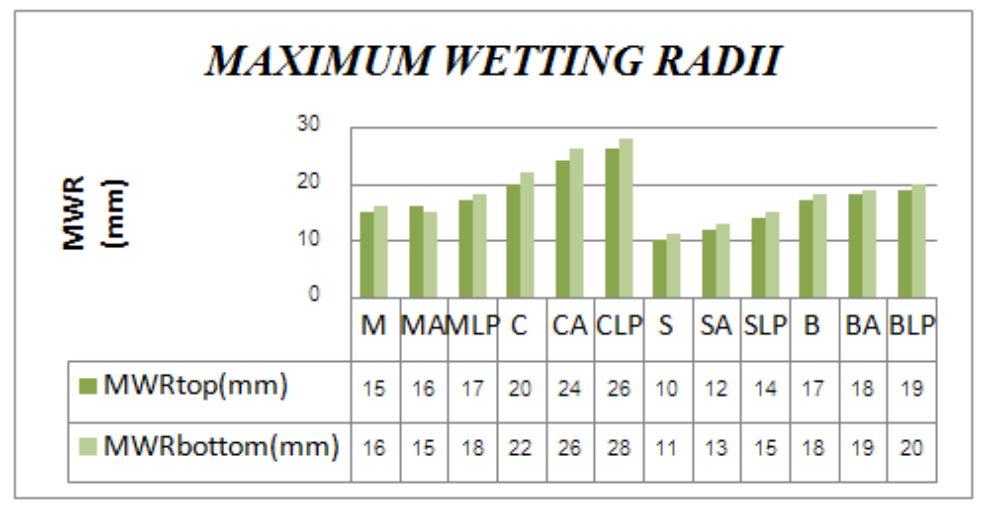

Figure 3

Figure 3 shows the maximum wetting radii of both top and bottom surface of selected knitted fabrics. In the study, the maximum wetted radius (MWR) of the fabrics wetted with the same amount of liquid is also investigated. The results for all the fabrics are given in Figure 3. It may be seen that the MWR is lower for the fabrics with lower thickness content. Because of the hydrophilic character of fiber, some of the liquid absorbed by the fibers would penetrate into the fiber structure, which results in lower moisture spreading along the fabric. In the test equipment used in this study the test specimen is so mounted as to have its top surface represent the inner surface of a clothing fabric that would normally be in touch with the skin.

It was observed that the dyed fabrics had slightly higher MWR when compared to controlled fabrics in all the selected knitted fabrics. Also pomegranate mordanted dyed fabrics had higher MWR in comparison with alum mordanted dyed fabrics. Therefore, a lower value of MWR for the top surface of the fabric means a less clammy touch, a less chilly sensation and thus overall better comfort close to the skin. Since the bamboo and modal fabrics had the lowest MWR 
values for the top surface of the fabrics, it reflects good moisture transport property and a dry feeling as a result.

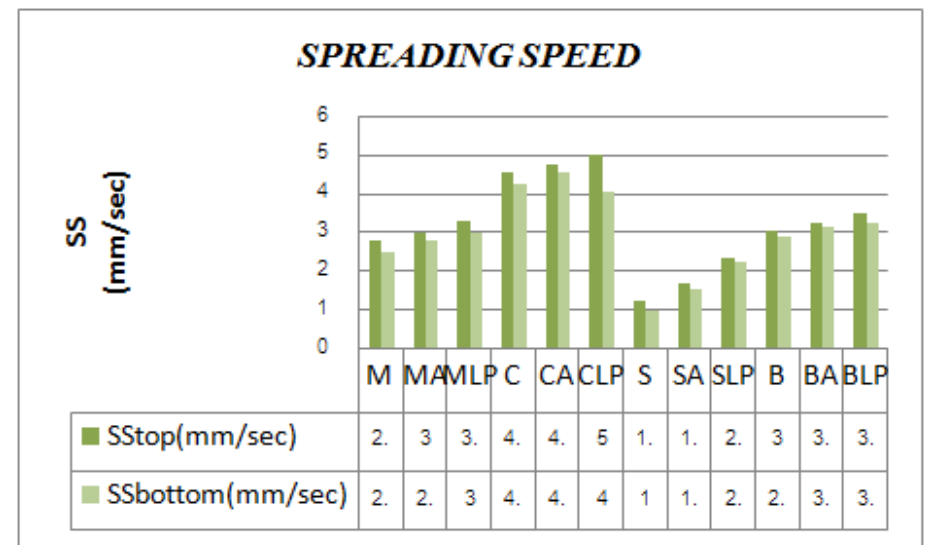

Figure 4

The water-spreading speed test results for the fabrics are given in Figure 4. Prakash et al $(2012)^{5}$ studied that spreading speed of the bamboo fabrics reduced due to the low porosity. Karthikeyan et al.(2016) ${ }^{6}$ noted that as the proportion of bamboo fiber increases, the porosity of the fabric reduces.

A comparison of the spreading speed values between dyed and controlled fabrics clearly reveals that the spreading speed decreases as the thickness decreases. It was noted earlier that with thinner fabrics the wetting time decreases, consequently spreading speed for the wetting of the thicker fabric are higher compared to the thinner fabric. This is probably also caused by the low porosity of fabrics.

\section{Effect of Dye on AOTI and OMMC}

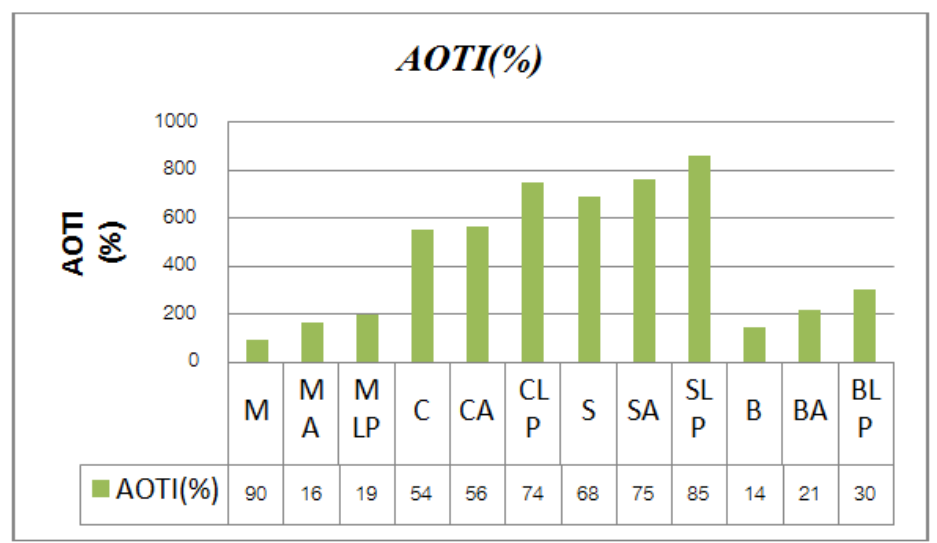

Figure 5 


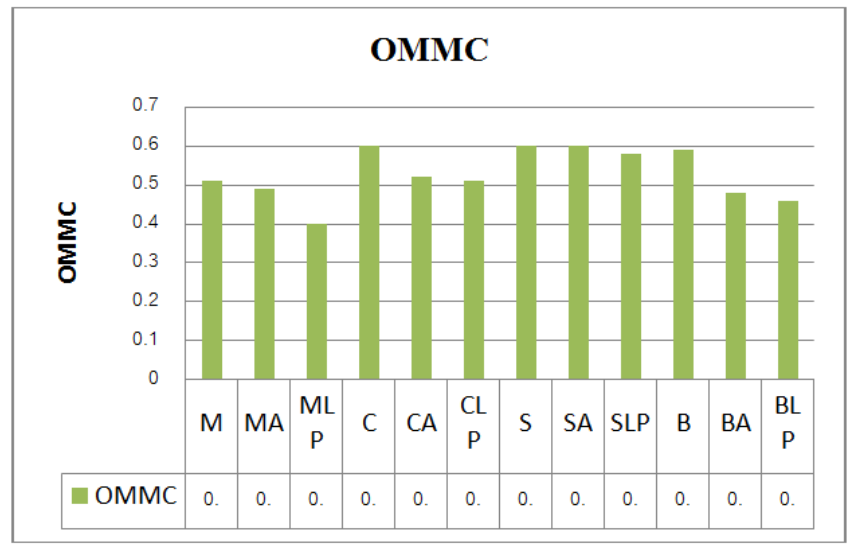

Figure 6

Figure 5 shows theAccumulative one-way transport index $(\%)$ of the elected knitted fabrics and Figure 6 shows the Overall moisture management capability of the selected knitted fabrics.

AOTI is the difference in the accumulative moisture content between the two surfaces of the fabric. AOTI reflects the one-way liquid transport capacity from the top (inner next to the skin) to the bottom (outer) surface of the fabric. The relationship between dyed and controlled fabrics with respect to AOTI and OMMC can be observed in the Figures 5 and 6. AOTI was influenced by dyeing. It is observed that BLP and MLP fabrics have 303.51 and 194.85 AOTI value compared to AOTI value of CLP (746.37) and SLP(853.6) fabrics. It can be inferred that the values of AOTI values of silk and cotton dyed fabrics are higher than those of bamboo and modal dyed fabrics. AOTI values are higher for cotton and silk.

This is probably due to the difference in accumulative moisture content between the two surfaces of the fabric in the given testing time, where at times, the moisture content on the top fabric surface is more than that on the bottom surface, and at times, the opposite is true.

The Overall Moisture Management Capability (OMMC) is dependent upon the absorption rate, one-way liquid transport index and liquid spreading speedYao et al ${ }^{7}$.

It is observed that BLP and MLP have 0.46 and 0.40 OMMC value when compared to CLP with 0.51 and SLP with0.58.

From the results, it can be stated that bamboo and modal fabrics have low OMMC value. This may be due to minimum thickness of the bamboo and modal fabrics as compared to the silk and cotton dyed fabrics. All the fabrics are in the 'good' category in terms of moisture management capacity. Most of the fabrics have a shorter wetting time for the top surface than for the bottom surface and all of the fabrics demonstrate higher absorption at the top surface than at the bottom surface.

\section{CONCLUSIONS}

In this study the moisture management properties of Cotton, Modal, Silk and Bamboo knitted fabrics were studied before and after dyeing with cannon ball fruit extract. It was noticed that in the undyed state cotton, silk and bamboo were identical in moisture absorption

This study mainly focuses on the effect of dye on the moisture management properties of the knitted fabrics. The results showed that as the pomegranate mordanted dyed fabrics, wetting time, maximum wetted radius and spreading speed 
but rate of absorption decreased and overall moisture management capacity decreased rate. The fabric thickness influence the moisture management properties significantly. It is concluded that as the pomegranate mordanted influences the increases the wetting time and maximum wetted radius. This means that with increase in thickness, more time is required to wet knitted fabrics. The overall moisture management capacity (OMMC) can serve as an indicator of the moisture behavior of the fabrics. All the fabrics in general were in the "good" category in terms of moisture management capacity.

\section{REFERENCES}

1. Hu J Y, Li Y, Yeung $K W$, Wong A S and Xu W, "Moisture Management Tester : a test method to characterize fabric liquid moisture management properties," Textile Research Journal,75, 2005, pp 57-62.

2. Jhanji Y, Gupta D and Kothari VK, "Moisture Mnagaement Properties of plated knit structures with varying fibre types," The Journal of Textile Institute, 106, 2015, pp 663 - 773.

3. Seif, A. M. (2014). Investigating The Seam Slippage of Satin Fabrics. International Journal of Textile and Fashion Technology, 4(5), 1-10.

4. G. Karthikeyan, G. Nalankilli, O.L. Shanmugasundram and C. Prakash, "Thermal comfort properties of bamboo tencel knitted fabrics, International Journal of Clothing Science and Technology," 2016, Vol. 28, No. 4, pp. 420-428.

5. C.Prakash, G.Ramakrishnan and C.V.Koushik, Effect of blend proportion on moisture management characteristics of bamboo/cotton knitted fabrics, Journal of The Textile Institute, December 2013 (Impact factor-0.77), Vol. 104, Issue 12, pp. 1320-1326,

6. C. Prakash and G. Ramakrishnan, Influence of blend ratio on thermal properties of bamboo/cotton blended woven fabrics, Silpakorn University Science \& Technology Journal, July 2012 (Impact factor-0.05),Vol. 6(2), pp. 47-53,

7. Khurana, K. Marketing As a Quintessential Tool for Growth of Ethiopian Textile and Garment Sector.

8. G. Karthikeyan, G. Nalankilli, O.L. Shanmugasundram and C. Prakash, Thermal comfort properties of bamboo tencel knitted fabrics, International Journal of Clothing Science and Technology, 2016, Vol. 28, No. 4, pp. 420-428.

9. Yao, $B G, L i, Y, H u, J Y, K w o k, Y L \&$ Yeung, $K W$, 'An improved test method for characterizing the dynamic liquid moisture transfer in porous polymeric materials', Polymer Testing,2006, vol. 25, no. 5, pp. 677-689. 